\title{
Hostility During Training: Historical Roots of Primary Care Disparagement
}

\author{
Joanna Veazey Brooks, PbD, MBE \\ School of Medicine, University of Kansas, \\ Kansas City, Kansas
}

\begin{abstract}
PURPOSE The environment during medical school has been shown to dissuade students from choosing primary care careers. The purpose of this study was (1) to explore how long-standing this hostility toward primary care is historically and (2) to understand the mechanisms through which the environment conveys disparagement of primary care to students.
\end{abstract}

METHODS The study is based on a qualitative analysis of 52 primary care physician oral histories. The data are from the Primary Care Oral History Collection, created by Fitzhugh Mullan and deposited in the National Library of Medicine. Transcripts were analyzed using qualitative data analysis and the constant comparative method.

RESULTS Respondents (63.5\%) reported experiencing discouragement or disparagement about primary care, and this proportion remained fairly high through 5 decades. Findings indicate that hostility toward primary care operates through the culture and the structure of medical training, creating barriers to the portrayal of primary care as appealing and important. Support for primary care choice was uncommon but was reported by some respondents.

CONCLUSION The primary care shortage and primary care's unfavorable representation during medical training is a multifaceted problem. The evidence reported here shows that cultural and structural factors are critical components of the problem, and have existed for decades. For policy responses to be most effective in meeting the primary care workforce problem, they must address the presence and power of persistent hostility against primary care during training.

Ann Fam Med 2016;14:446-452. doi: 10.1370/afm.1971.

\section{INTRODUCTION}

$\mathrm{P}$ romoting and maintaining an adequate supply of primary care physicians is extremely important for the US health care system. Primary care has been shown to improve health, increase access to health care, reduce health care disparities, and lower health care costs. ${ }^{1-3} \mathrm{Geo-}$ graphic areas with more primary care physicians have lower overall costs and lower rates of preventable hospitalizations. ${ }^{14-6}$ In fact, the Organisation for Economic Co-operation and Development attributes the United States' extremely high health expenditures to an underdeveloped primary care sector. ${ }^{7}$

Despite the benefits of primary care, the future of primary care has been described as precarious. ${ }^{8}$ Researchers project a shortage of 33,000 primary care physicians by $2035,{ }^{9}$ a number that is driven by a growing and aging population and by insurance expansion through the Patient Protection and Affordable Care Act. ${ }^{10-12}$ Maldistribution of primary care physicians is another serious aspect of the shortage. ${ }^{12,13}$

Given a growing need for first-contact, coordinated, patient-centered care that primary care provides, ${ }^{1,14-16}$ the number of US medical graduates choosing to practice primary care medicine is inadequate. ${ }^{17}$ There is evidence that fourth-year students find primary care less attractive than first-year students, ${ }^{18}$ and only $39 \%$ of medical students who were origi- 
nally interested in family medicine ended up choosing it. ${ }^{19}$ Although numerous factors influence individual career decisions, researchers report that the medical school environment is chilly towards primary care. ${ }^{20}$ In fact, the Council on Graduate Medical Education has highlighted the medical school environment as a key obstacle for advancing primary care. ${ }^{21}$

Although the medical school environment has been shown to be problematic for recruiting primary care physicians, less is known about how the devaluing of primary care is communicated to students during training or about the presence of these problems historically. Using data from the Primary Care Oral History Collection, ${ }^{22}$ I used historical analysis ${ }^{23,24}$ to investigate whether cultural and structural aspects of hostility toward primary care during training have persisted through time. A better understanding of the full contours of obstacles for primary care, as well as their potential intransigence, is necessary to inform the most effective current responses for the primary care workforce problem today.

\section{DATA AND METHODS}

For this report, I analyzed data from the Primary Care Oral History Collection, which includes oral histories of 52 physicians. The collection was donated to the National Library of Medicine by Fitzhugh Mullan, a historian and pediatrician, who conducted the oral histories from 1995 to 1996. Mullan includes 15 condensed oral histories in his book Big Doctoring in America: Profiles in Primary Care and deposited all oral histories for public access and the "use of future scholars." ${ }^{24}$ Mullan reported using snowball sampling, although he tried to "keep a balance with regard to geography, gender, urban/rural practice, ethnicity, and discipline." ${ }^{25}$ Mullan was interested in interviewing physicians with "experience and perspective" and recognizes that this aim likely resulted in targeting more senior and accomplished physicians. Oral histories and historical analysis are well-accepted methodologies in history and historical sociology. ${ }^{23,24,26}$ Oral histories are particularly well-suited to gather contextually rich data and capture "frustrations and disappointments." 24

The combined length of the oral histories used for this article is 3,244 typed pages in the format publicly available, which averages to approximately 62 pages per respondent. The 52 physicians are from 3 different primary care fields: family medicine, general internal medicine, and general pediatrics. One respondent practiced both generalist and specialist medicine. Although the content of each interview is unique, the interviewee consistently discusses early influences on the choice of a medical career and then addresses the development of a career and personal life. The span of this oral history data (covering medical graduation years from 1936 to 1985) is able to provide data on experiences through multiple decades.

Analysis was conducted at the University of Pennsylvania and is exempt from Institutional Review Board review because of the public nature of the data. Oral history transcripts were uploaded and analyzed using NVivo 9 qualitative data analysis software (QSR International). The entire content of oral histories was carefully analyzed line by line by the author using open coding, allowing themes to emerge inductively and following the principles of qualitative analysis methodologies. ${ }^{28-31}$ Disparagement of primary care developed inductively as a common theme in most, but not all, of the oral histories. Negative case analysis was also conducted to identify exceptions to this common theme. Contrasting cases, in which respondents did not mention disparagement and/or reported receiving support for their primary care decision, are also examined below. Each interview excerpt is identified by the respondent's primary care specialty (family medicine, general internal medicine, general pediatrics, or general practice), the name of the medical school, and the graduation year.

\section{RESULTS}

\section{Study Sample}

The 52 oral histories analyzed here are organized into medical school graduation cohorts (Table 1).

\section{Trends in Disparagement, 1936-1985}

Of the total respondents, $63.5 \%$ indicated that they were discouraged by others about their interest in primary care or that others disparaged primary care. Table 2 displays these findings across 10 -year cohorts, grouped according to when respondents graduated from medical school.

Disparagement toward primary care has persisted at a relatively constant level through these decades, suggesting that institutional hostility is not a new phenomenon and is at least somewhat entrenched and persistent (Table 2). Through analysis, disparagement emerged through 2 key mechanisms: (1) culture, which includes individual and group attitudes and behaviors; and (2) structure, which refers to institutional level organization and makeup.

\section{Cultural Hostility}

Respondents describe accounts of primary care disparagement, beginning as early as the medical school application process. Applicants, hoping to enter the profession of medicine, were told with varied degrees 
Table 1. Respondents by Sex and 10-Year Medical School Graduation Year Cohort

\begin{tabular}{lcccc}
\hline & \multicolumn{3}{c}{ Respondents } & \\
\cline { 2 - 4 } $\begin{array}{l}\text { Graduation } \\
\text { Year Cohort }\end{array}$ & $\begin{array}{c}\text { Male } \\
\text { No. }\end{array}$ & $\begin{array}{c}\text { Female } \\
\text { No. }\end{array}$ & $\begin{array}{c}\text { Total } \\
\text { No. }\end{array}$ & $\begin{array}{c}\text { Cohort as } \\
\text { \% of Total }\end{array}$ \\
\hline $1936-1945$ & 2 & 1 & 3 & 5.8 \\
$1946-1955$ & 7 & 1 & 8 & 15.4 \\
$1956-1965$ & 8 & 3 & 11 & 21.2 \\
$1966-1975$ & 13 & 2 & 15 & 28.8 \\
$1976-1985$ & 7 & 8 & 15 & 28.8 \\
Total & 37 & 15 & 52 & 100.0 \\
\hline
\end{tabular}

Data from: Mullan F. Primary care oral history collection. http://www.ncbi.nlm. nih.gov/nlmcatalog/101166350. ${ }^{22}$

\section{Table 2. Respondents Reporting Disparagement for Choice of Primary Care Specialty, by Medical School Graduation Year Cohort}

\begin{tabular}{lcc}
\hline $\begin{array}{l}\text { Graduation } \\
\text { Year Cohort }\end{array}$ & $\begin{array}{c}\text { Reporting } \\
\text { Disparagement } \\
\% \text { (No.) }\end{array}$ & $\begin{array}{c}\text { Total No. of } \\
\text { Respondents }\end{array}$ \\
\hline $1936-1945$ & $66.7(2)$ & 3 \\
$1946-1955$ & $75.0(6)$ & 8 \\
$1956-1965$ & $63.6(7)$ & 11 \\
$1966-1975$ & $46.7(7)$ & 15 \\
$1976-1985$ & $73.3(11)$ & 15 \\
\hline Data from: Mullan F. Primary care oral history collection. http://www.ncbi.nlm. \\
nih.gov/nlmcatalog/101166350.22
\end{tabular}

of bluntness that primary care aspirations were unwelcome. Before their official training began, recruits stumbled upon clear messages during interviews that conveyed that certain fields were honored and certain fields were to be avoided.

I...talked to some students, and they asked me how the conversation went with the dean. They said, "Well, did you tell him what you wanted to be?" I said, "Well, yeah. I said I wanted to be a family doctor." And they all sort of looked around like this, and said, "Well, that was the wrong thing to say." [Laughter] And as it turned out, it probably was the wrong thing to say (family medicine, Thomas Jefferson University 1979).

Clearly, if you mentioned the word "general practitioner," you had said something terribly wrong. He asked me, he said, "Well, what kind of physician do you want to be?" And I said, "A general practitioner." And he spent the next 20 minutes berating me, and telling me that I could go to a GP school if I wanted to, but [school name] produced specialists, and was a cut above that kind of interest (pediatrics, Tufts University School of Medicine 1964).

For other respondents, an awareness of the low status of primary care physicians within medicine emerged later, after their medical education began. Students expressing a desire to practice generalist medicine during training received messages that being intelligent and professional were incompatible with choosing primary care, that they were "too smart" for primary care medicine. One respondent described choosing primary care as a disappointment to faculty:

When I first started as a generalist that was not the thing to do...the attitude was that if you were in general medicine, then you were too dumb to get a fellowship. I remember one of my former professors came over to give grand rounds.... I hadn't seen him for a couple of years, and he said, "Gosh, hey...what are you doing?" And I said, "Well, you know, I'm in general medicine..." and you would have thought I said I'd been in jail for 2 years. The look on his face told me that [I] somehow failed. I think that was sort of a prevailing attitude, that there wasn't much merit in generalism (internal medicine, University of Minnesota Medical School 1971).

This quote demonstrates a strong response: choosing primary care was framed as a failure and no better than time in jail. Another facet of the cultural hostility took the form of attack on primary care physicians in the community, who were routinely mocked and belittled.

I didn't feel encouragement about doing general practice. In those days it was the LMD, the local medical doctor, who was always considered the low person on the totem pole in terms of intellect (family medicine, Indiana University School of Medicine 1965).

All my life in academic medicine I had had this picture of the practicing physician out there in the community that was somewhat distorted. I don't know whether I thought of them as not quite as bright as the academics or what but it was certainly that flavor that was transmitted by the academic environment (generalist/subspecialist, Harvard Medical School 1973).

\section{Structural Hostility}

Numerous historical factors contributed to the structural underrepresentation of primary care faculty in training settings, which created embedded obstacles for primary care. Particularly after World War II, government funding and legislation enabled and accelerated specialization. ${ }^{31}$ In addition, increased government money for research made medical schools dependent on specialists whose research could secure NIH grants and other sources of funding. ${ }^{32}$

The real shift resulted from the post-World War II federal policy of subsidizing full-time faculty in all the med schools. That guaranteed specialism: the peer models that the medical students got were specialists who, because they chose to go academic, were making a statement that they placed research and education above practice. I could dilate on that, but I 
think it's a terribly important event, a cultural and academic event. Mind you, who picks the incoming students? The faculty. Who trains them and who tells them what to do with their career as they're leaving? This same faculty almost to a man-mostly a man, an occasional woman-were specialists. So that rapid transformation was facilitated, I think fortuitously, by the generous decision of the public through the federal government to fund full-time faculty (internal medicine, Northwestern University School of Medicine 1947),

The resulting medical schools housed faculty who were almost entirely committed to specialist medicine. ${ }^{3-36}$ A structural environment was created with very few primary care mentors and role models during training. ${ }^{37,38}$

And I think, in those days, as you went through medical school, there were no people in medical school who said to you, "Be a general practitioner..." You never saw a family physician...I mean, I didn't see anybody (pediatrics, Tufts University School of Medicine 1964).

I think that was certainly reinforced when you went to [school name]-I'm not certain any medical school would have been different in the fifties - that you had no generalist faculty role models to whom you were exposed (pediatrics, Harvard Medical School 1956).

By failing to include many primary care faculty, the specialist makeup of medical schools is often then reproduced, potentially making primary care an uncharted career choice for students.

The content of medical training creates structural hostility as well because it is ill suited to illuminate the typical work of a generalist physician.

It's hard, because there's no way to know what general internal medicine is, on the basis of a medical residency in a hospital. It just ain't there. I mean, there's no overlap, all the things you do as a medical resident, while it gives you a lot of knowledge and certain skills, has very little to do with the real life of a practicing internist which is overwhelming with outpatients. Now a surgeon, I think, he's learning in the hospital what he's going to be doing. He's doing what he's going to do. The internist doesn't (internal medicine, Northwestern University School of Medicine 1947).

When students inclined toward primary care were at the point of choosing their field of medicine, they were rarely exposed to the content they would encounter in day-to-day practice as a primary care physician. Structural hostility is also of consequence because the very benefits seen as most rewarding by primary care physicians cannot be easily known through the structure of medical education. Further, the structure, which lacked primary care mentors and provided little exposure to the content of primary care medicine, conveys a normative stance that specialty medicine is the way of medicine; it promulgates the "idea that there was no other way" (internal medicine, Columbia University College of Physicians and Surgeons 1985).

\section{Support for Primary Care Choice}

Analysis also exposed exceptions to the theme of hostility, in which respondents either (1) talked about experiencing support for their interest in primary care or (2) simply did not mention disparagement in regard to their primary care choice.

Some respondents described receiving support for their primary care choice from mentors and peers. One respondent decided to work at the same institution where she did her training because,

I had mentors within the institution that were really encouraging me to stay, primary care doctors.... So I felt that you could be primary care oriented and survive (internal medicine, Columbia University College of Physicians and Surgeons 1985).

Even at schools where choosing primary care was unusual, the response of leadership to an interest in primary care was occasionally positive. For example, one respondent (family medicine, Rutgers Medical School 1975) shared that he was intrigued by family medicine, but could not find any physicians in the specialty at his school. He met with his dean, who willingly connected him with a generalist in the community who then served as a key mentor. Finally, one respondent explained that strong peer support encouraged her primary care specialty choice:

I had an extraordinarily interesting class.... My classmates were such an enriching experience in many ways. That particular class turned out one of the highest percentages of primary care physicians... (family medicine, Harvard Medical School 1982).

Although supportive mentors and peers were scarce in most cases, their encouragement was powerful when present.

\section{The Role of Gender}

Of the respondents who did not explicitly report disparagement, differences emerged by the gender of the respondent. First, a smaller percentage of female respondents reported disparagement overall $(53 \% ; 8$ of 15$)$ compared with male respondents $(67.6 \% ; 25$ of 37 ). Second, of the women who graduated from medical school in earlier cohorts, before 1977, only 2 (22.2\%) reported disparagement about choosing primary care, where as $100 \%$ of women graduating after 1976 reported it. Notably, of the 7 women graduating before 1977 who did not report disparagement about 
choosing primary care, 5 did discuss difficulties and obstacles to choosing medicine as a woman. For example, these respondents reported finding it harder to get into medical school as a woman (pediatrics, Tufts University School of Medicine 1949; family medicine, Columbia University College of Physicians and Surgeons 1969), or being the only woman in her medical school class (family medicine, University of Vermont College of Medicine 1936).

\section{DISCUSSION}

For this report I analyzed oral histories and illuminated the historical nature of hostility toward primary care during medical training. Findings show that $63.5 \%$ of respondents reported hostility toward primary care, embedded in both cultural and structural aspects of medical training. The historical nature of this data informs how deeply rooted and entrenched hostility has been for primary care, an essential and oftenoverlooked component of the primary care workforce problem. These findings also evidence that medical schools do not simply teach scientific knowledge; they also impart values and attitudes through a hidden curriculum. ${ }^{39-41}$ The hostility reported here creates barriers to the portrayal of primary care as appealing and rewarding.

The experiences represented here may not be representative of those of all primary care physicians during these decades or of all medical school environments. In addition, oral histories, as retrospective accounts, are limited in their ability to describe realtime events. Oral histories are particularly able to enhance understanding about the formative nature of a hostile culture, however, as vivid descriptions of primary care disparagement decades after the fact demonstrate its lasting power.

The hostility toward primary care reported here from historical data has not disappeared in the current environment. Several recent studies have identified the importance of culture, ${ }^{42-45}$ providing more evidence that medical training can contribute to trainees' disinterest in primary care. ${ }^{43,46,47}$ Additionally, the structure of medical education continues to emphasize specialty medicine while the content and rewards of primary care are all to frequently overlooked. ${ }^{20}$

Some respondents offered examples of positive support for navigating the hostile structure and culture of medical school, pointing to possible responses to the problem. Respondents reported that they were able to push back against the negativity toward primary care when they had meaningful peer and/or mentor support. ${ }^{48}$ Patient relationships also emerged as a central motivation for practicing primary care, a reward that offset the obstacles and frustrations for many respondents. Thus, bolstering primary care faculty in medical schools and highlighting primary care rewards could help encourage students to choose primary care.

Differences in reporting disparagement by gender were also present. Although the small sample size prohibits conclusions, it could be that women in the earlier cohorts primarily dealt with the discouragement and challenges they faced as women entering a historically male-dominated profession. The struggle of proving oneself as a woman in medicine could have eclipsed the struggles associated with choosing primary care medicine. Or, perhaps female respondents actually experienced less discouragement from choosing a primary care career because its lower status was seen as a more appropriate specialty for women than for men. ${ }^{49}$ For the more recent cohorts, the feminization of medicine potentially allowed women to experience fewer obstacles because of their gender and to therefore report more discouragement about choosing primary caredisparagement that their male counterparts, who did not struggle because of the status of their gender, had been consistently experiencing and reporting. Research should continue to explore the impact of interactions between multiple sources of hostility and disparagement for individuals' specialty choices.

It is worth noting that the need for more primary care physicians is a common refrain, even within the medical community. Researchers examining decades of medical education reform proposals reveal a theme of "the need to avoid over-specialization" 50 and the importance of "fostering generalism. ${ }^{\text {"51 }}$ In fact, medical education scholars find that despite repeated and consistent calls for reform, a general resistance to change exists within medical education. ${ }^{39,52}$ This caution, combined with the deep roots of hostility toward primary care found in this analysis, suggest that the culture and structure maintaining the primary care shortage will not change quickly or easily. For encouraging policy recommendations intended to increase the supply of primary care physicians to maximize their desired outcomes ${ }_{1}^{13,21}$ we must recognize the role of noneconomic factors in contributing to the problem.

The primary care shortage, as well as primary care's unfavorable representation during training, is a multifaceted problem. As evidenced here, cultural and structural problems are critical components of the problem. The demand for more primary care physicians shows no sign of abating. Bloom poses the simple yet poignant question: "Are we training doctors for the real needs of the population?"52 Understanding and changing the way that hostility operates through the culture and structure of medical training is essential to answering the same question affirmatively in the future. 
To read or post commentaries in response to this article, see it online at http://www.annfammed.org/content/14/5/446.

Key words: general practice; medical education; medical schools; socialization; hidden curriculum

Submitted August 13, 2015; submitted, revised, February 11, 2016; accepted March 10, 2016.

Funding support: This research was supported by a Gertrude $\&$ Otto Pollak Summer Research Fellowship from the University of Pennsylvania and through the Robert Wood Johnson Foundation Scholars in Health Policy Research Program.

Acknowledgments: Antoinette Peters, Sabrina Danielsen, Gawin Tsai, Ksenia Gorbenko, Charles Bosk, Jason Schnittker, Robin Leidner, Diana Khuu, Jennifer Justice, and John Veazey provided helpful comments.

\section{References}

1. Starfield B, Shi L, Macinko J. Contribution of primary care to health systems and health. Milbank Q. 2005;83(3):457-502.

2. Starfield B. The future of primary care: refocusing the system. $N$ Engl J Med. 2008;359(20):2087-2091, 2091.

3. Stewart AL, Grumbach K, Osmond DH, Vranizan K, Komaromy M, Bindman AB. Primary care and patient perceptions of access to care. J Fam Pract. 1997;44(2):177-185.

4. Fisher ES, Wennberg DE, Stukel TA, Gottlieb DJ, Lucas FL, Pinder EL. The implications of regional variations in Medicare spending. Part 1: the content, quality, and accessibility of care. Ann Intern Med. 2003;138(4):273-287.

5. Parchman ML, Culler S. Primary care physicians and avoidable hospitalizations. J Fam Pract. 1994;39(2):123-128.

6. Welch WP, Miller ME, Welch HG, Fisher ES, Wennberg JE. Geographic variation in expenditures for physicians' services in the United States. N Engl J Med. 1993;328(9):621-627.

7. Organisation for Economic Cooperation and Development. Why the US health spending is so high. http://www.oecd.org/health/healthsystems/49084355.pdf. Published 2011. Accessed May 1, 2015.

8. Boulis AK, Jacobs JA. The Changing Face of Medicine: Women Doctors and the Evolution of Health Care in America. New York, NY: Cornell University Press; 2008.

9. Petterson SM, Liaw WR, Tran C, Bazemore AW. Estimating the residency expansion required to avoid projected primary care physician shortages by 2035. Ann Fam Med. 2015;13(2):107-114.

10. Petterson SM, Liaw WR, Phillips RL Jr, Rabin DL, Meyers DS, Bazemore AW. Projecting US primary care physician workforce needs: 2010-2025. Ann Fam Med. 2012;10(6):503-509.

11. Mechanic D, Rochefort DA. Comparative medical systems. Annu Rev Sociol. 1996;22:239-270.

12. Goodell S, Dower C, O'Neil E. Primary care workforce in the United States. Robert Wood Johns Found. 2011;Policy Brief No.22.

13. Dower C, O'Neil E. Primary care health workforce in the United States. Research Synthesis Report No. 22. https://folio.iupui.edu/ bitstream/handle/10244/983/070811. policysynthesis.workforce.rpt. pdf. Published Jul 2011.

14. Kimball HR, Young PR. A statement on the generalist physician from the american boards of family practice and internal medicine. JAMA. 1994;271(4):315-316.

15. Starfield B. Is primary care essential? Lancet. 1994;344(8930): 1129-1133.

16. Starfield B. Primary Care: Balancing Health Needs, Services, and Technology. New York, NY: Oxford University Press; 1998.
17. American Academy of Family Physicians. 2012 Match Summary and Analysis. Jun 2012. http://www.aafp.org/online/en/home/residents/ match/summary.html.

18. Lynch DC, Newton DA, Grayson MS, Whitley TW. Influence of medical school on medical students' opinions about primary care practice. Acad Med. 1998;73(4):433-435.

19. Hearst N, Shore WB, Hudes ES, French L. Family practice bashing as perceived by students at a university medical center. Fam Med. 1995;27(6):366-370.

20. Block SD, Clark-Chiarelli N, Peters AS, Singer JD. Academia's chilly climate for primary care. JAMA. 1996;276(9):677-682.

21. Council on Graduate Medical Education. Advancing primary care. http://www.hrsa.gov/advisorycommittees/bhpradvisory/cogme/ Reports/twentiethreport.pdf. Published Dec 2010.

22. Mullan F. Primary care oral history collection. 1995-1996. OH 146. Located at: History of Medicine Division, National Library of Medicine, Bethesda, MD. http://www.ncbi.nlm.nih.gov/ nlmcatalog/101166350.

23. Söderquist T, ed. The Historiography of Contemporary Science and Technology. Amsterdam, the Netherlands: Routledge; 1997.

24. Mullan F. Big Doctoring in America: Profiles in Primary Care. Berkeley, CA: University of California Press; 2004.

25. Mullan F. Profiles in primary care. JAMA. 1998;279(14):1115-1116.

26. Haines E. Let's talk about science: a critical analysis of oral history practices in HSTM. http://www.academia.edu/14624896/Lets_Talk_ About_Science_A_Critical_Analysis_of_Oral_History_Practices_in_ HSTM. Published 2010. Accessed Dec 11, 2015.

27. Glaser B, Strauss A. The Discovery of Grounded Theory: Strategies for Qualitative Research. New Brunswick, NJ: Aldine Transaction; 1999.

28. Strauss A, Corbin JM. Basics of Qualitative Research: Grounded Theory Procedures and Techniques. Second Edition edition. Newbury Park, CA: Sage Publications, Inc; 1990.

29. Charmaz K. Constructing Grounded Theory: A Practical Guide through Qualitative Analysis. 1 edition. Thousand Oaks, CA: Sage Publications Ltd; 2006.

30. Starks H, Trinidad SB. Choose your method: a comparison of phenomenology, discourse analysis, and grounded theory. Qual Health Res. 2007;17(10):1372-1380.

31. Arroyo I. The Emergence of Family Practice: A Sociological Perspective [dissertation]. San Fransisco: University of California; 1986.

32. Cadmus RR. Next step in specialization. JAMA. 1964;189(5):378-380.

33. Purtell RF. General practitioners' duty as medical teachers. GP. 1955;12(1):145-146.

34. Fullerton WW. General practice. III Med J. 1955;107(1):46-48.

35. Land FL. Medical education. General practice residence programs. Nebr State Med J. 1962;47:668-672.

36. Lewis HP. The broad internist and the subspecialist. Their roles in teaching and patient care. Trans Am Clin Climatol Assoc. 1969;80:1-6.

37. Alvey CR. The family physician as an educator. JAMA. 1961;177(11): 763-764.

38. Rardin TE. Medical students, family doctors, and family practice. JAMA. 1961;176(6):479-482.

39. Hafferty FW. Beyond curriculum reform: confronting medicine's hidden curriculum. Acad Med. 1998;73(4):403-407.

40. Hafferty FW, Franks R. The hidden curriculum, ethics teaching, and the structure of medical education. Acad Med. 1994;69(11):861-871.

41. Hundert EM, Douglas-Steele D, Bickel J. Context in medical education: the informal ethics curriculum. Med Educ. 1996;30(5):353-364.

42. Dupras DM, West CP. Training for careers in primary care: time for attention to culture. J Gen Intern Med. 2015;30(9):1243-1244. 
43. Kernan WN, Elnicki DM, Hauer KE. The selling of primary care. 2015. J Gen Intern Med. 2015;30(9):1376-1380.

44. Pfarrwaller E, Sommer J, Chung C, et al. Impact of interventions to increase the proportion of medical students choosing a primary care career: a systematic review. J Gen Intern Med. 2015;30(9): 1349-1358.

45. Erikson CE, Danish S, Jones KC, Sandberg SF, Carle AC. The role of medical school culture in primary care career choice. Acad Med. 2013;88(12):1919-1926.

46. Stanley M, O'Brien $B$, Julian $\mathrm{K}$, et al. Is training in a primary care internal medicine residency associated with a career in primary care medicine? J Gen Intern Med. 2015;30(9):1333-1338.

47. Jolly P, Erikson C, Garrison GUS. U.S. graduate medical education and physician specialty choice. Acad Med. 2013;88(4):468-474.
48. Kutob RM, Senf JH, Campos-Outcalt D. The diverse functions of role models across primary care specialties. Fam Med. 2006;38(4): 244-251.

49. Bourne PG, Wikler NJ. Commitment and the cultural mandate: women in medicine. Soc Probl. 1978;25(4):430-440.

50. Whitehead CR, Hodges BD, Austin Z. Captive on a carousel: discourses of 'new' in medical education 1910-2010. Adv Health Sci Educ Theory Pract. 2013;18(4):755-768.

51. Christakis NA. The similarity and frequency of proposals to reform US medical education. Constant concerns. JAMA. 1995;274(9): 706-711.

52. Bloom SW. The medical school as a social organization: the sources of resistance to change. Med Educ. 1989;23(3):228-241.

\section{CHANGE-OF-ADDRESS FORM FAMMILY MEDICINE}

Please complete this form and mail to the following address or fax to Annals Circulation at 913-906-6080:

Annals of Family Medicine, Circulation Department, 11400 Tomahawk Creek Pkwy, Leawood, KS 66211-2680

Check if member of sponsoring organization:

$\square$ AAFP $\square$ ABFM $\square$ STFM $\square$ ADFM
$\square$ AFMRD $\square$ NAPCRG $\square$ CFPC

ID number from label on your journal cover

OLD Information (Please print.)

Name

Company (if applicable)

Address (Street plus Apt or Ste)

City

Country Postal Code (9-digit ZIP for US)

Telephone

Fax

E-Mail
NEW Information (Please print.)

\begin{tabular}{ll}
\hline Name & \\
\hline Company (if applicable) & \\
\hline Address (Street plus Apt or Ste) & \\
\hline City & Postal Code (9-digit ZIP for US) \\
\hline Country & \\
\hline Telephone & \\
\hline E-Mail & \\
\hline
\end{tabular}

